\title{
A retrospective analysis of intravenous acetaminophen use in spinal surgery patients
}

\author{
April N. SMled (first version): $\quad 31-J a n-2014$
Recepted: 14-Jul-2014
}

\begin{abstract}
${ }^{*}$
Objective: This study aimed to determine if intravenous acetaminophen [paracetamol] (IV APAP) could decrease visual analog pain scores (VAS), opioid exposure and subsequent opioid related adverse effects (nausea, vomiting, constipation) in spinal surgery patients. Methods: Thirty four spinal surgery patients to date have received IV APAP since its addition to the formulary at our institution. The electronic medical record was accessed on all patients who received at least one dose pre or post operatively to collect postoperative opioid consumption (in morphine equivalents), number of antiemetic and laxative doses, use of naloxone, and VAS pain scores from arrival to surgical unit through postop day two. An equivalent number of patients who did not receive any IV APAP were selected and matched on the basis of opioid use prior to admission, surgery type, surgeon, age, and sex to constitute the control group.

Results: The IV APAP group used significantly less opioids than the control group $(p=0.015)$. Frequency of antiemetic and laxative use and VAS pain scores did not differ significantly between the two groups.

Conclusions: It appears IV APAP can be used effectively as an adjuvant pain management therapy in spinal surgery patients to decrease opioid exposure, but does not necessarily reduce the incidence of opioid related adverse effects or VAS pain scores.
\end{abstract}

Keywords: Acetaminophen; Analgesics, Opioid; Pain Management; Pain, Postoperative; Spinal Diseases; Comparative Effectiveness Research; United States

\footnotetext{
April N. SMITH. PharmD., BCPS. Assistant Professor in the Department of Pharmacy Practice, School of Pharmacy \& Health Professions, Creighton University. Omaha, NE (United States). april.smith@creighton.edu Vie C. HOEFLING. School of Pharmacy \& Health Professions, Creighton University. Omaha, NE (United States).
}

\section{INTRODUCTION}

Opioids have long since been the cornerstone of acute postoperative pain management. While opioids are fast and effective at controlling postoperative pain, they are not without considerable adverse effects. The most common opioid-related side-effects include nausea, vomiting and constipation and the most serious include respiratory depression. All of these adverse effects have a high potential to lead to additional medications administered, lower patient satisfaction scores, and increased cost and length of stay. Clinicians have struggled to find pain management regimens that maximize efficacy and patient satisfaction while minimizing adverse effects. Acetaminophen has been used alongside opioids for the management of mild to moderate pain for decades. Until recently it was only available in the United States in oral and rectal dosage forms. In contrast, intravenous acetaminophen (paracetamol) has been used consistently in Europe and other countries for the management of mild to moderate acute pain. In comparison to the intravenous route, oral preparations have a slower onset of action and rectal forms have lower bioavailability. ${ }^{1}$ According to a study by Yale University's Anesthesiology Department, this drug formulation has shown positive effects in orthopedic surgery patients reporting moderate to severe pain by demonstrating a quicker onset of action and reducing pain within the first 24 hours postop. ${ }^{2}$ It has been studied as monotherapy and as a multimodal therapy with adjuvant opioid analgesics. In addition, a repeated dose study of two intravenous acetaminophen (IV APAP) regimens, $1000 \mathrm{mg} q 6 \mathrm{~h}$ and $650 \mathrm{mg} q 4 \mathrm{~h}$, showed that both regimens significantly reduced postoperative pain intensity in laparoscopic abdominal surgery patients. ${ }^{3}$

As of November of 2010, IV APAP became available in the United States and marketed as Ofirmev ${ }^{\circledR}$ by Cadence Pharmaceuticals. Since then, patient studies in a variety of surgical populations, such as appendectomy, cesarean section, and hip fracture have shown significant decreases in pain intensity over the first 24 hours postoperatively and decreased opioid utilization. ${ }^{4}$ However, IV APAP has yet to be studied in other surgical populations such as spinal surgery. In January 2013, IV APAP was added to the formulary at Alegent Creighton Health. Dosing for IV APAP is $1000 \mathrm{mg} / 100 \mathrm{~mL}$, infused over 15 minutes every six hours. ${ }^{4}$ This route of administration does increase nurse administration time and cost versus oral or rectal routes. However, it could be hypothesized that using IV APAP as an 


\begin{tabular}{|l|c|c|c|}
\hline \multicolumn{1}{|c|}{ Table 1. Baseline Characteristics } & \multicolumn{4}{l|}{ Patient demographics } & IV APAP (n=34) & Control $(\mathrm{n}=34)$ & P values \\
\hline Age. mean (SD) & $50.8(19.4)$ & $49.9(19.0)$ & 0.917 \\
\hline Height. (in) mean (SD) & $66.7(3.0)$ & $66.8(3.6)$ & 0.325 \\
\hline Weight. (kg) mean (SD) & $85.0(16.7)$ & $82.7(21.1)$ & 0.331 \\
\hline Gender. (\% female) & 76.5 & 73.5 & 1.000 \\
\hline Opioid PTA (\% yes) & 35.3 & 35.3 & 1.000 \\
\hline Average operative time. min (SD) & $216.0(114.4)$ & $187.5(93.9)$ & 0.264 \\
\hline
\end{tabular}

adjuvant pain management therapy could lead to less opioid use and thus decreased antiemetic and laxative consumption. This study aimed to determine whether IV APAP usage in spinal surgery patients significantly reduced postoperative opioid use and opioid related side-effects.

\section{METHODS}

The research protocol for this study was a retrospective electronic chart review approved by the Creighton University institutional review board. The electronic medical record was accessed on all patients who received at least one dose of IV APAP pre or post operatively to collect postoperative opioid consumption (in morphine equivalents), number of antiemetic and laxative doses, use of naloxone, and visual analog pain scores (VAS) from arrival to surgical unit through postop day two. Thirty four spinal surgery patients to date have received IV APAP since its addition to the formulary at our institution. All patients in the study underwent spinal fusion with either an anterior or posterior approach. An equivalent number of patients who did not receive any IV APAP were selected during the same study period and matched on the basis of opioid use prior to admission (PTA), surgery type and approach, surgeon, age, and sex to constitute the control group. Any patient who received epidural or intrathecal opioid was excluded from the study. Relevant patient demographic information was collected on all patients including age, sex, height, weight, use of opioid PTA and operative time (Table 1). Any patient who had a current, valid prescription for any opioid and reported using that medication within one week prior to surgery was counted as "Yes" on the demographic qualitative assessment of opioid PTA.

Of patients who received IV APAP, all but one patient received a preoperative dose of $1000 \mathrm{mg}$ infused over 15 minutes. On average, patients in the IV APAP group received four postoperative doses. Patients in both groups were allowed intravenous and oral opioids on an as needed basis for postoperative pain management. Total opioid doses were taken from medication administration records and converted to morphine equivalents (ME) using the GlobalRPh online calculator with a $25 \%$ reduction for incomplete cross tolerance. Starting day of surgery, upon arrival to patient care unit, all opioid consumption (IV and PO) was collected through postop day two and totaled for each respective day. Use of tapentadol, buprenorphine, and nalbuphine was allowed however, these were not included in the morphine equivalent calculation because there is no universally acceptable conversion factor. At least one dose of tapentadol was used by three patients in the IV APAP group. Eight patients in the IV APAP group and four in the control group received at least one dose of buprenorphine. One patient in the control group received one dose of nalbuphine. VAS pain scores were recorded as an average for each respective day. Numbers of antiemetic and laxative doses used were totaled for each respective day. Antiemetics and laxatives included both scheduled and as needed rescue doses per the standard postoperative spinal surgery order set.

Patient demographic characteristics were compared between the IV APAP and control group using descriptive statistics. Mixed design ANOVA was conducted to evaluate the changes of postoperative opioid utilization and VAS pain scores over the three time points (day of surgery, postoperative day 1 , and postoperative day 2) within each group and between the two groups overall during the study period. Pearson Chi-Square tests were performed to compare cumulative antiemetic and laxative utilization between the two groups. SPSS Statistics 20 (IBM Corporation, Somers, New York) was used for all data analysis and a p-value less than 0.05 was considered significant.

\section{RESULTS}

For each day studied, as well as averaged for the entire study period, the IV APAP group showed significantly less opioid utilization than the control group (Figure 1). Overall, the IV APAP group used a daily average of $11.3 \mathrm{mg}$ ME versus $20.6 \mathrm{mg}$ in the control group $(p=0.015)$. Only one dose of naloxone was administered and it was to a patient in the control group. VAS pain scores averaged over the entire study period were not significantly different between the two groups (5.6 for IV APAP versus 5.1 for control; $p=0.116$ ). Neither antiemetic nor laxative use differed significantly between the two groups for the overall study period ( $p=0.666$ for antiemetics and $p=0.683$ for laxatives). Numbers of patients in each group were categorized by those who required zero, one, or more than one antiemetic or laxative during the period studied and were totaled and reported as frequency of use (Figure 2). Therefore, with thirty four patients in each group and a study period of three days, frequency could not exceed 102 for any antiemetic or laxative use category. 


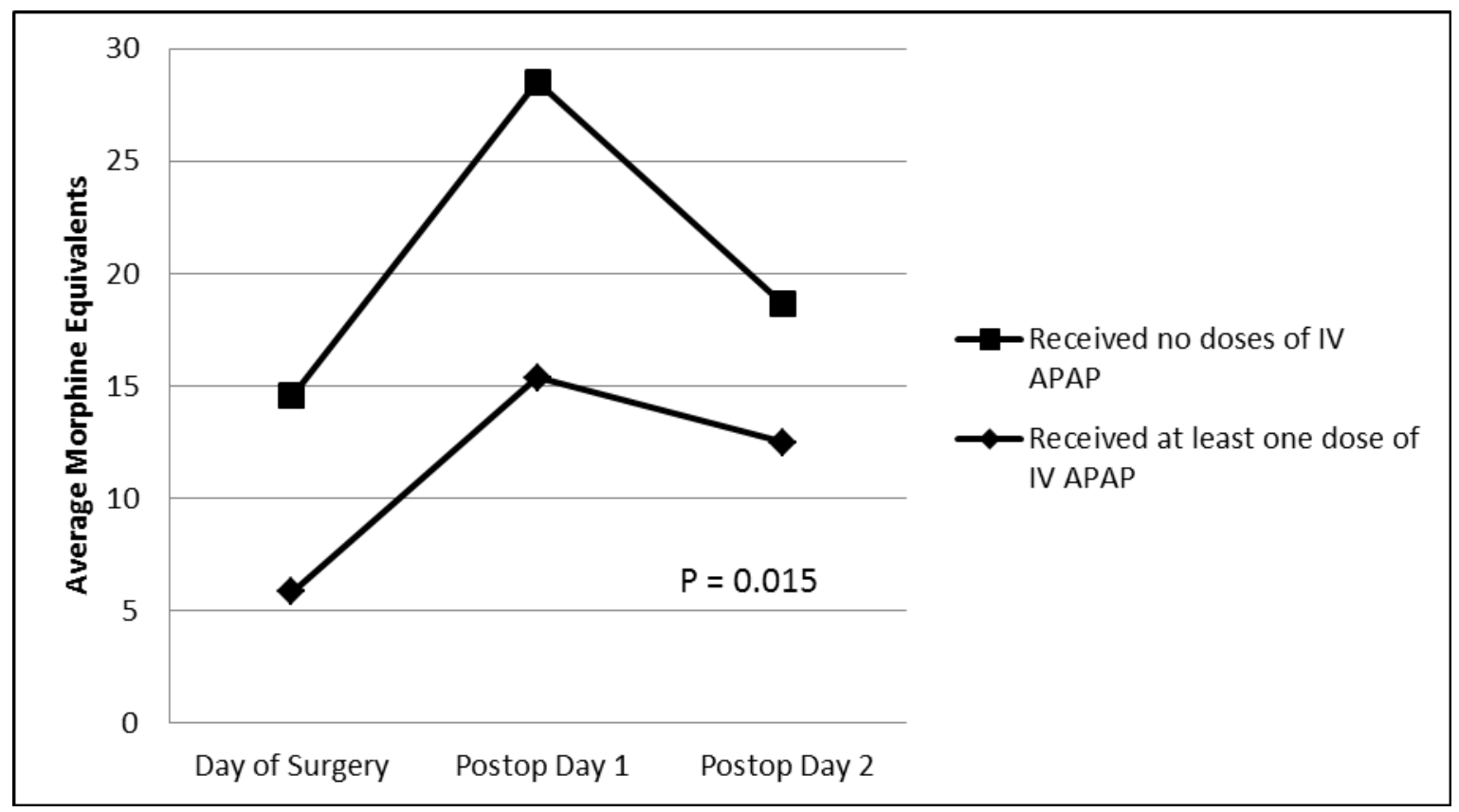

Figure 1. Average opioid utilization (in morphine equivalents) for spinal surgery patients with and without intravenous acetaminophen.

\section{DISCUSSION}

We have demonstrated that spinal surgery patients who received IV APAP showed significantly less post-operative opioid consumption compared to the control group. These results are consistent with current literature addressing IV APAP usage in other surgical populations. However, some previous studies of IV APAP in surgical patients showed a decrease in patient VAS pain scores, which was not demonstrated in our population. Some of these previously published studies also claim increased patient satisfaction scores with regard to pain control when IV APAP was used. ${ }^{2}$ Due to the retrospective nature of our study design, patient satisfaction scores specifically related to pain control could not be extracted from the electronic medical record. Of note, VAS pain scores were not required to be assessed at regular intervals so variability in nursing care could have potentially influenced this outcome.

Despite decreased opioid-utilization, the IV APAP group did not show a statistically significant reduction in antiemetic and laxative use in comparison to the control group. Thus, antiemetic and laxative frequency in both spinal surgery patient groups appears to remain consistent regardless of their level of opioid consumption. As with VAS pain scores, gastrointestinal distress was not assessed at predefined intervals so variability in nursing care and/or patient sensitivity could have potentially influenced this outcome. With laxative and antiemetic use, naloxone administration, and length of stay being similar between both groups, it appears the decreased opioid utilization shown by the IV APAP group did not translate to decreased incidence of typical opioid-related adverse events.

Even though our study was not prospective and randomized, all IV APAP patients were successfully matched to an appropriate control patient on the basis of opioid PTA, surgery type and approach, surgeon, and sex. Limitations included inconsistent documentation of patient pain scores, which only added to the subjectivity of the VAS pain score system, and potential selection bias of the matched control group. Statistical software used did not allow for missing VAS pain scores for any patient day. Patients who did not have a VAS pain score documented for a particular day were excluded from the data analysis for VAS pain scores (four patients in each group) but were still included for opioid utilization and antiemetic and laxative use. Concurrent use of tapentadol, buprenorphine, and nalbuphine was allowed for all patients and not included in the opioid utilization total which could represent a limitation of this study. However,

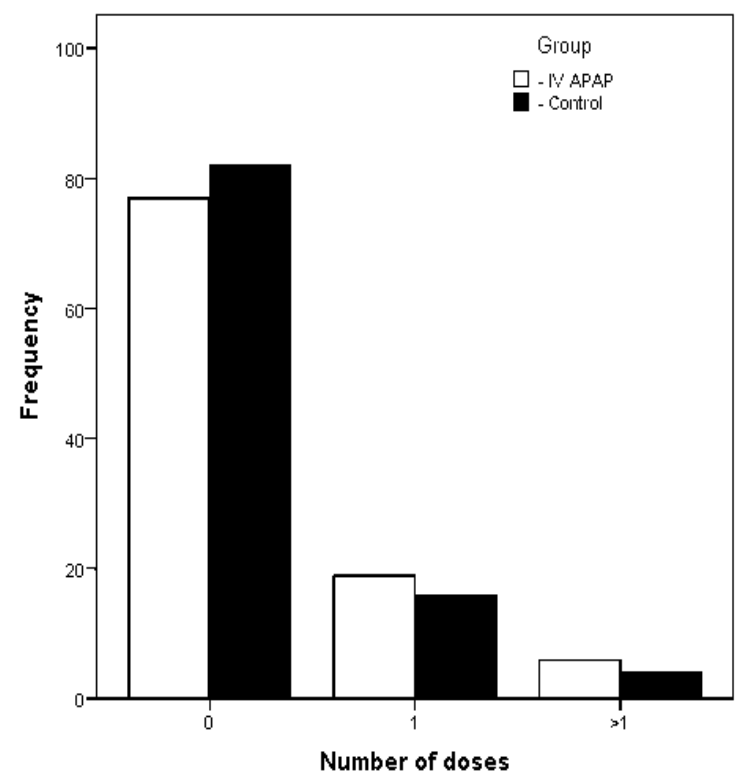

Figure 2. Cumulative antiemetic utilization for spinal surgery patients with and without intravenous acetaminophen. 
utilization of these ancillary agents was relatively low and distributed between the two study groups which we believe did not bias our overall results. Oral acetaminophen use was allowed (only after stopping IV APAP in the study group) either alone or in combination with hydrocodone or oxycodone. Total oral acetaminophen consumption was not recorded for either group, which maybe could have influenced the results. However, we don't believe this would have impacted the results strongly given the nature of these surgeries usually requires opioid medications for adequate post-operative pain control.

Another limitation was the novelty of IV APAP at our institution and subsequent limited number of patients to constitute the IV APAP group. Since the new formulation was only recently added to the formulary in January of 2013 , our facility had only utilized IV APAP in 34 surgical patients. We acknowledge that the study could be even more compelling given a larger experimental group. Due to the rapidly growing popularity of IV APAP specifically amongst spinal surgeons at our institution, we desired a spot analysis of the impact of IV APAP to determine if its utilization in this patient population should be continued or discouraged. We also realize that the study had different surgeons. However, we believe that any differences are negligible given that technique, surgical approach, operative time, and anesthesia were similar between groups and each control patient was matched on several factors including same surgeon. All patients in the study underwent surgery during the same 12 month time period in attempt to minimize any potential fluctuations in surgical technique or instruments. Despite the small size of both groups, the goal of establishing the utility of IV APAP in spinal surgery patients was achieved.

Although cost analysis was not performed in this study, consideration of cost would be beneficial for both patients and hospital administrators who are considering its addition to formulary and assessing its pattern of use. Since intravenous acetaminophen has been proven to be an effective adjunctive pain management therapy to traditional opioids, preoperative and postoperative oral dosages may prove just as efficacious but at a significantly lower price and less risk in terms of manipulation of the patient's IV site. While it is difficult to compare relative efficacy of IV versus oral APAP in terms of pain satisfaction between various surgery types, current literature seems inconclusive on the superiority of IV to oral APAP for this outcome. ${ }^{6}$ Literature does exist to demonstrate faster attainment of Cmax and more consistent therapeutic blood levels of IV versus oral APAP but the relevance to clinical outcomes remains largely unseen. 7,8

\section{CONCLUSIONS}

It appears that spinal surgery patients at our institution who received IV APAP had decreased postoperative opioid utilization, but similar VAS pain scores. Despite decreased opioid utilization, the IV APAP group had similar antiemetic and laxative usage compared to the control group. Based on these data, it appears IV APAP can be used effectively as an adjuvant pain management therapy in spinal surgery patients to decrease their opioid exposure. Larger studies should be done to explore the utility of IV APAP in specific surgical populations.

\section{ACKNOWLEDGMENTS}

We acknowledge Yongyue Qi for his assistance with the statistical analysis of our data. Mr. Qi is a statistician at the Creighton University School of Pharmacy and Health Professions.

\section{CONFLICT OF INTEREST}

The authors have no conflicts of interest to disclose.

Funding Information: No funding was received for this project.

\section{ANÁLISIS RETROSPECTIVO DEL USO DE PARACETAMOL INTRAVENOSO EN PACIENTES CON CIRUGÍA MEDULAR}

\section{RESUMEN}

Objetivo: Este estudio trato de determinar si el paracetamol [acetaminofén] intravenoso (IV APAP) podría disminuir la puntuación de la escala visual analógica del dolor (VAS), el uso de opioides y los subsiguientes efectos adversos de los opioides (nausea, vómitos, estreñimiento) en pacientes con cirugía medular.

Métodos: En nuestra institución, hasta la fecha, 34 pacientes con cirugía medular han recibido IV APAP desde su incorporación al formulario. Para recoger el consumo post-operatorio de opioides (en equivalentes de morfina), el número de antieméticos y las dosis de laxantes, uso de naloxona, así como las puntuaciones de la VAS de dolor, se accedió a las historias clínicas electrónicas de todos los pacientes que recibieron al menos una dosis pre o post-operatoria desde su ingreso en la unidad quirúrgica hasta el día 2 post-operatorio. Para constituir el grupo control, se seleccionó un número equivalente de pacientes que no recibió IV APAP y se emparejó en base a uso de opioides previo al ingreso, tipo de cirugía, cirujano, edad y sexo.

Resultados: El grupo IV APAP utilizó

significativamente menos opioides que el grupo control $(\mathrm{p}=0,015)$. La frecuencia de uso de antieméticos y laxantes y las puntuaciones de la VAS de dolor no fueron significativamente diferentes en los dos grupos.

Conclusiones: Parece que el IV APAP puede usarse efectivamente como adyuvante del tratamiento del dolor en pacientes con cirugía medular para disminuir la exposición a opioides, aunque no necesariamente se reduce la incidencia de efectos adversos de los opioides o las puntuaciones de la VAS de dolor.

Palabras clave: Paracetamol; Analgésicos Opioides; Manejo del Dolor; Dolor Postoperatorio; Enfermedades de la Columna Vertebral; Investigación sobre la Eficacia Comparativa; Estados Unidos 


\section{References}

1. Acetaminophen monograph. Clinical Pharmacology 2014. Gold Standard, Elsevier. Online database. http://www.goldstandard.com/ (Accessed June 3, 2014).

2. Sinatra RS, Jahr JS, Reynolds LW, Viscusi ER, Groudine SB, Payen-Champenois C. Efficacy and safety of single and repeated administration of $1 \mathrm{gram}$ intravenous acetaminophen injection (paracetamol) for pain management after major orthopedic surgery. Anesthesiology. 2005;102(4):822-831.

3. Wininger SJ, Miller H, Minkowitz HS, Royal MA, Ang RY, Breitmeyer JB, Singla NK. A randomized, double-blind, placebo-controlled, multicenter, repeat-dose study of two intravenous acetaminophen dosing regimens for the treatment of pain after abdominal laparoscopic surgery. Clin Ther. 2010;32(14):2348-2369. doi: 10.1016/j.clinthera.2010.12.011

4. OFIRMEV® (acetaminophen) injection prescribing information. Cadence Pharmaceuticals, Inc. San Diego, CA. Revised 10-2013.

5. Memis D, Inal MT, Kavalci G, Sezer A, Sut N. Intravenous paracetamol reduced the use of opioids, extubation time, and opioid-related adverse effects after major surgery in intensive care unit. J Crit Care. 2010;25(3):458-462. doi: 10.1016/j.jcrc.2009.12.012

6. Fenlon S, Collyer J, Giles J, Bidd H, Lees M, Nicholson J, Dulai R, Hankins M, Edelman N. Oral vs intravenous paracetamol for lower third molar extractions under general anaesthesia: is oral administration inferior? $\mathrm{Br} \mathrm{J}$ Anaesth. 2013;110(3):432-437. doi: 10.1093/bja/aes387

7. Brett CN, Barnett SG, Pearson J. Postoperative plasma paracetamol levels following oral or intravenous paracetamol administration: a double-blind randomised controlled trial. Anaesth Intensive Care. 2012;40(1):166-171.

8. van der Westhuizen J, Kuo PY, Reed PW, Holder K. Randomised controlled trial comparing oral and intravenous paracetamol (acetaminophen) plasma levels when given as preoperative analgesia. Anaesth Intensive Care. 2011;39(2):242-246. 